Sir,

\section{Mistaken eye drops and subsequent instillation of superglue}

A 60-year-old man presented himself to the casualty department after accidentally instilling superglue into his eyes. He had traditionally put eye drops in himself in the evening. On this occasion he had mistaken his wife's fingernail glue for the eye drops as it stood on the bedside cabinet. The bottles were very similar in reduced light, as both were a dropper design for delivery and the same compact size.

Once the glue, of which the major constituent was cyanoacrylate, contacted his eye it caused immense sudden pain causing him to close his eye more. The glue then set quickly and thus he presented with a permanently closed eye. The upper lid was adherent to the cornea, as when the eye movements were tested the lid moved.

He was followed up and after two consultations he was able to fully open his eye and his vision returned to normal. This outcome was also found in two other studies where 6 and 14 patients were followed up. ${ }^{1,2}$

Suggestions to avoid this type of accident include: childproof bottles, ${ }^{3}$ different colours of cap for different drugs, a Braille warning on bottles, vertical ribs on glue bottles to signify a warning, posters in the A and E department, and giving glues a different odour to alert the user. This case adds weight to previous reports indicating that this accident still occurs and is very distressing to the patient, who becomes instantly blind in the injured eye.

\section{References}

1. Lyons C, Stevens J, Bloom J. Super-glue inadvertently used as eyedrops [letter]. BMJ 1990;300:328.

2. McClean CJ. Ocular super-glue injury. J Accident Emerg Med 1997;14:40-1.

3. Good AM, McCabe SE. Super-glue accidents and the eye: causes and prevention [letter]. Br J Ophthalmol 1994;78:802.

\section{I.J. Knight}

Cotswold Place

Camberlot Road

Upper Dicker

Hallsham

E. Sussex BN27 3RQ, UK

Tel: $+44(0) 1634830000$

\section{Sir,}

Rimexolone-induced intraocular pressure elevation Topical administration of corticosteroids inhibits the inflammatory response to mechanical, chemical or immunological agents. Their precise mechanism of action is unknown, but the effects of corticosteroids include inhibition of inflammatory mediator production, inhibition of leucocytes and phagocyte migration in the acute inflammatory response, and inhibition of fibroblast proliferation and collagen deposition. ${ }^{1}$ Corticosteroids are effective in suppressing the inflammatory process, but are also associated with undesirable side-effects which include the elevation of intraocular pressure (IOP) in susceptible (steroid-responsive) patients. Rimexolone $1 \%$ ophthalmic suspension is a recently developed topical corticosteroid with effective anti-inflammatory properties as well as a reduced risk of increased IOP. ${ }^{2,3}$ We present a case report of a patient with markedly elevated IOP associated with the use of $1 \%$ rimexolone suspension.

\section{Case report}

A 52-year-old woman with a history of toxic epidermal necrolysis has been attending our institution since 1992 . As a result of her condition she developed dry eyes which required punctal occlusion and eye lubricants, including autologous serum drops. She had marked keratinisation of the tarsal conjunctiva especially in the left eye, which necessitated mucous membrane grafting. Her condition was further complicated by metaplastic eyelashes, which were treated with cryotherapy. She subsequently developed a corneal ulcer in the left eye which persisted for a long period despite aggressive treatment. During the healing stage of the ulcer, $0.5 \%$ prednisolone sodium phosphate (Predsol) three times daily was commenced. The baseline IOP was $14 \mathrm{mmHg}$ in the right eye and $12 \mathrm{mmHg}$ in the left, and gonioscopy revealed open angles. During the course of her treatment she was found to be a steroid responder. The baseline IOP increased by $16-20 \mathrm{mmHg}$ with Predsol three times daily. Because of the need to continue using topical corticosteroids, she was instructed to use timolol $0.5 \%$ twice daily. After a few months of treatment the IOP started increasing again. Fundoscopy revealed glaucomatous optic disc cupping in the left eye only, and perimetry demonstrated glaucomatous field defect. Latanoprost was added to her treatment, which helped in reducing the IOP.

When rimexolone $1 \%$ suspension became available, Predsol was discontinued and she was asked to use rimexolone three times daily instead. Before initiating rimexolone, the IOP was $26 \mathrm{mmHg}$ in the left eye. Two weeks later the IOP went down to $14 \mathrm{mmHg}$. The IOP was maintained within the normal range until about 3 months later when it was found to be $42 \mathrm{mmHg}$. Rimexolone was stopped and on follow-up examination 1 week later the IOP returned to $15 \mathrm{mmHg}$. Rimexolone was reintroduced 3 weeks later and again the IOP increased to $40 \mathrm{mmHg}$, but on this occasion the rise occurred within 2 weeks of treatment. Rimexolone was discontinued, and the IOP went down to $14 \mathrm{mmHg}$ after 1 week. The IOP in the right eye (which did not receive any corticosteroid) remained normal and fundoscopy showed a healthy disc throughout her clinic visits.

\section{Comment}

The relatively new ophthalmic preparation, rimexolone, is a synthetic non-fluorinated corticosteroid. Structurally, it contains a methyl group at the $\mathrm{C}-21$ position. Omission of the hydroxyl group at C-21 and substitution of a 